\title{
An Incidental Finding of Enormous Number of Multiple Gall Stones in a Tertiary Setup in Western India
}

\author{
Authors \\ Dr Shirish Bhagvat ${ }^{1}$, Dr Khushagra Rahul ${ }^{2}$, Dr Ali Zaid Anwar ${ }^{3}$, \\ Dr Sudaiv Nagzarkar ${ }^{4}$, Dr Jalbaji More ${ }^{5}$, Dr Supriya Bhondve ${ }^{6}$, Dr Saad Sheikh ${ }^{7}$
}

\begin{abstract}
In this case report we state the occurrence of 800 gall stone found in a single patient undergoing elective cholecystectomy. The largest number of the gallstone found in a single patient is 11970.the occurrence of gallstone is fairly common in a tropical country like India but the occurrence of multiple gall stone is comparatively rare.
\end{abstract}

Keywords: multiple gall stones.

\section{Introduction}

Gall stones are a common disease of the biliary tree and the incidence of gall stones has appeared to be on the rise and the gall bladder disease is a frequent problem in the developing countries ${ }^{(1,2)}$. Gallstones are a case of chronic recurrent hepatobiliary disease tand is mainly due to impairment of of the metabolism of cholesterol, bilirubin and bile acids ${ }^{(1,3)}$. This disease has a considerable impact socially and economically ${ }^{(4)}$ Prevalence of gallstones in India is more in females than men. The presence was more common in Northern India than Southern India followed by Maharashtra region ${ }^{(5)}$.

The patient who had come to us hailed form an interior district on Maharashtra and was found to be on a high cholesterol and was hence predisposed to gall stones ${ }^{(6)}$ and was operated successfully with no post operative complication.

Post operatively the patient underwent a repeat sonography to exclude the slippage of any stones into the common bile duct and the liver functions were also repeated to exclude any blockage

\section{Case Report}

We report a case of 57 year old male who came to us 2 months ago with abdominal pain which was intermittent and colicky in nature he also had complaints of vomiting which was non projectile non bilious and contained mostly food particles. $\mathrm{He}$ also had intermittent attacks of fever which was low grade in nature and was sometimes associated with rigors and chills, murphy's sign was also positive. An abdominal sonogram was carried out which revealed an acutely inflamed gall bladder .The white blood counts were raised to $17000 / \mathrm{cu} . \mathrm{mm}$ and the liver function tests was within normal limits .Patient was managed conservatively with antibiotics and keeping him nil by mouth later the patient was discharged and asked to follow up after 6 weeks for elective cholecystectomy 
After 6 weeks the patient was admitted and was taken up for elective cholecystectomy which was done using laprascopy as shown in the image given.

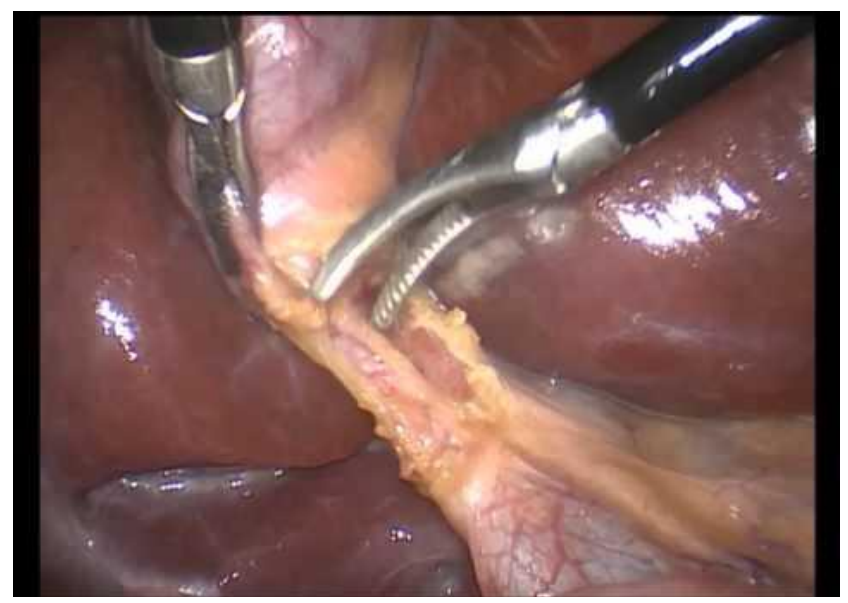

In the operation the gall bladder appeared to be normal and using minimal dissection the procedure was accomplished the gall bladder was removed successfully. After the operation the specimen was taken up to be examined for any abnormalities and within it a huge number of gall stones were found. The stones were examined and were counted to amount to be 836 as shown in the image given and the gall bladder wall appeared to be slightly thickened

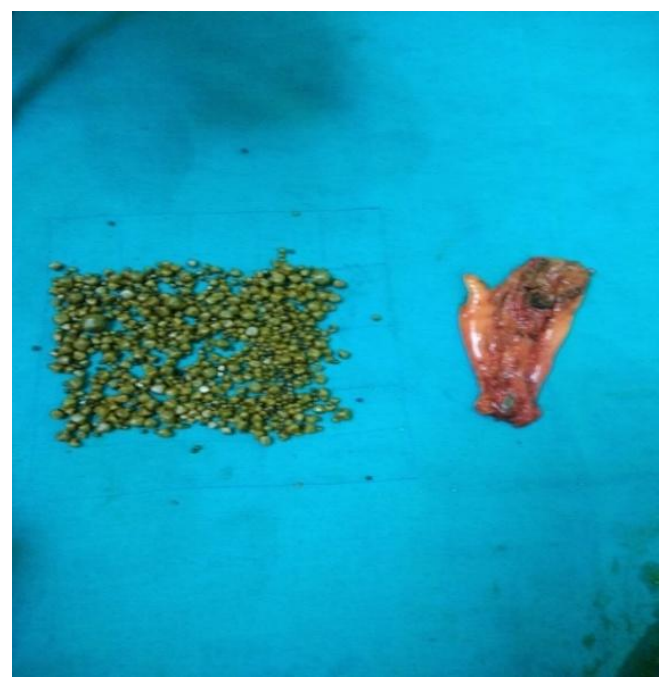

\section{Discussion}

Gallstones are crystalized forms of the bile, that can form within the gallbladder. They vary in size and shape. Gallstones occur when there is an imbalance in the chemical constituents of bile that result in precipitation of one or more of the components.

There are 4 stages of cholelithiasis

1. Stage of formation ( stage of lithogenesis)

2. Stage of asymptomatic gall stones

3. Stage of symptomatic gall stones

4. Stage of complicated gall stones

Once gallstones becomes symptomatic the operation is indicated and must be carried out as soon as possible within 48 hours or electively at a later date preferably after 6 weeks.

On the basis of composition, gall stones can be divided into the three types ${ }^{(7)}$

\section{Cholesterol stones}

These stones can range from yellow to dark green or brown or chalk white, usually solitary. To be classified as such, they must contain at least $80 \%$ cholesterol by weight (or 70\%, according to the Japanese-classification system).Between $35 \%$ and $90 \%$ of stones are cholesterol stones. ${ }^{(7)}$

\section{Bilirubin stones}

These stones are small, dark (often appearing black), and usually numerous. They are composed primarily of bilirubin (insoluble bilirubin pigment polymer) and calcium (calcium phosphate) salts that are found in bile. They contain less than $20 \%$ of cholesterol ${ }^{(7)}$

\section{Mixed stones}

Mixed ("Brown Pigment") stones contain 20-80\% cholesterol. They arise secondary to infection of the biliary tract. Other common constituents are calcium carbonate and palmitatephosphate and other bile pigment. ${ }^{(7)}$

The formation of multiple gall stones has been theorised in many ways the most recited is due to temporary occlusion of the duct leading to supersaturation of the bile with calcium nbilirubinate or carbonate and in case of multiple stones there is addition of multiple choleterol crystals leading to the change in nature of stone. ${ }^{(8)}$

\section{Conclusion}

Thus the finding of this multiple gall stones is rare and is mainly due to the unique interaction 
between the cholesterol and pigment crystals as well each specimen should be dissected with arduos care to prevent prevent slippage of such stones further into the biliary tree preventing any further complications.

\section{References}

1. Johnston DE, Kaplan MM. Pathogenesis and treatment of gallstones. N Engl J Med. 1993;328:412-21

2. Shaffer EA. Epidemiology and risk factors for gallstone disease: Has the paradigm changed in the 21st century? CurrGastroenterol Rep. 2005;7(2):132-40

3. Belousov Yu V. Pediatric Gastroenterology. Up-to- date Guide. Moscow: Exma; 2006: 112

4. Temel RE, Brown JM. A new framework for reverse cholesterol transport: Nonbiliary contributions to reverse cholesterol transport. World J Gastroenterol 2010;16(47):5946-52

5. Bansal A et al. IntSurg J. 2014 Nov;1(3):134-139

6. Mohan H, Punia RPS, Dhawan SB, Ahal S, Sekhon MS. Morphological spectrum of gallstone disease in 1100 cholecystectomies in North India. Indian J Surg. 2005;67:140-2.

7. Lee, JY; Keane, MG; Pereira, S (June 2015). "Diagnosis and treatment of gallstone disease.". The Practitioner. 259 (1783): 15-9, 2. PMID 26455113

8. Wolpers et al ,solitary versus multiple gall stone .mechanism of formation and growth Clin investig.1993 Jun;71(6):423-34. 